\title{
Pengelolaan Program Parenting di TK IT X Kecamatan Ibun
}

\author{
Wilin Irania* \\ Prodi Pendidikan Guru PAUD, Fakultas Tarbiyah dan Keguruan, \\ Universitas Islam Bandung, Indonesia. \\ *wilin.irania@gmail.com
}

\begin{abstract}
Parenting services are an integral part of the PAUD program, which involves parents and the community. There are various kinds of problems faced by PAUD institutions in implementing parenting programs starting from preparation, implementation, and evaluation. This study aims to describe: (1) preparation (2) implementation (3) and evaluation of the parenting program in Kindergarten IT Mutiara Embun Pagi (4) as well as the results of the parenting program felt by parents of students at Kindergarten IT Mutiara Embun Pagi. This study uses a descriptive method with a qualitative approach that aims to describe an incident during the research process at Kindergarten IT Mutiara Embun Pagi. Primary data sources are principals, teachers, and parents of the Kindergarten IT Mutiara Embun Pagi. Qualitative interview data collection techniques (Qualitative Interview), Qualitative Audio and Visual Materials (Qualitative audio and visual materials), Qualitative Observations (Qualitative observations). Data analysis was carried out in stages, namely (1) data reduction, (2) data presentation, (3) conclusion drawing and verification. The validity of the data through credibility (Triangulation or triangulation and Referencial Adequacy Checks) transferability, dependability, and confirmability. The results showed that: (1) Of the 6 activities in the preparation stage of the parenting program, only 2 activities were carried out in TK IT X (2) Of the 5 forms of implementation of the parenting program, only 1 was not implemented in Kindergarten IT Mutiara Embun Pagi, namely a visit to home, (3) Of the 3 forms of evaluation, only 2 methods were used in evaluation activities, (4) parents felt the benefits of the parenting program, namely increasing parental insight regarding parenting so that they changed parenting patterns at home.
\end{abstract}

Keywords: parenting program, parenting, early childhood education.

Abstrak. Layanan parenting menjadi salah satu program yang tidak terpisahkan dari program PAUD, yang mana melibatkan orang tua dan masyarakat. Terdapat berbagai macam persoalan yang dihadapi lembaga PAUD dalam melaksanakan program parenting mulai dari persiapan, pelaksanaan, dan evaluasi. Penelitian ini bertujuan menggambarkan: (1) persiapan (2) pelaksanaan (3) dan evaluasi program parenting di TK IT X (4) serta hasil program parenting yang di rasakan oleh orang tua siswa di TK IT X. Penelitian ini menggunakan metode deskriptif dengan pendekatan kualitatif yang bertujuan menggambarkan suatu kejadian selama terjadinya proses penelitian di TK IT X. Sumber data primer adalah kepala sekolah, guru, dan orang tua murid di TK IT X. Teknik pengumpulan data wawancara kualitatif (Qualitatif Interview), Meteri Audio dan Visual Kualitatif (Qualitatif audio and visual materials), Observasi Kualitatif (Qualitatif Observation). Pengelolaan data dilakukan secara bertahap yaitu (1) Reduksi data, (2) Penyajian data (3) Penarikan simpulan dan verifikasi. Keabsahan data melalui credibility (Triangulation atau triangulasi dan Referencial Adequacy Checks) transferability, dependability, dan confirmability. Hasil penelitian menunjukkan bahwa: (1) Dari 6 kegiatan pada tahap persiapan program parenting hanya 2 kegiatan yang terlaksana di TK IT X (2) Dari 5 bentuk pelaksanaan program parenting hanya 1 yang tidak terlaksana di TK IT X yaitu kungjungan ke rumah, (3) Dari 3 bentuk evaluasi hanya 2 metode yang digunakan dalam kegiatan evaluasi, (4) orang tua merasakan manfaat adanya program parenting yaitu bertambahnya wawasan orang tua terkait parenting sehingga mengubah pola asuh di rumah.

Kata Kunci: Program parenting, parenting, pendidikan anak usia dini. 


\section{A. Pendahuluan}

Pendidikan di Indonesia memiliki tujuan : agar peserta didik secara aktif mengembangkan potensi dirinya untuk memiliki kekuatan spiritual keagamaan, pengendalian diri, kepribadian, kecerdasan, akhlak mulia, serta keterampilan yang diperlukan dirinya, masyarakat, bangsa dan negara (Undang Undang Republik Indonesia Nomor 20 Tahun 2003 Tentang Sistem Pendidikan Nasional, 2003) sedangkan Pendidikan anak usia dini memiliki tujuan mengembangkan setiap aspek perkembangan yang dimiliki anak, agar dapat berkembang secara optimal (masnipal, 2018 , p. 9) beragamnya tujuan dari pendidikan tersebut dapat tercapai apabila pendidikan anak di rumah dengan pendidikan anak di sekolah memilki keselarasan karena orang tua memiliki peran yang sangat penting dalam kehidupan anak. Menurut Ki Hajar Dewantara mengatakan bahwa "Keluarga adalah lingkungan pendidikan yang pertama dan utama" (1)

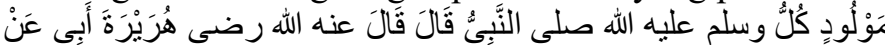

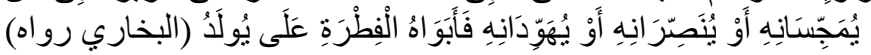

Artinya :

Dari Abu Hurairah ra, berkata: Nabi Muhammad SAW bersabda: "Setiap anak yang dilahirkan adalah dalam keadaan suci, maka kedua orang tuanyalah yang membuatnya menjadi Yahudi, Nasrani, atau Majusi". (Sahih Bukhari, No. hadis: 1401).

Selain itu pendidikan merupakan hal terbaik yang dapat orang tua berikan kepada anak hal tersebut berdasarkan:

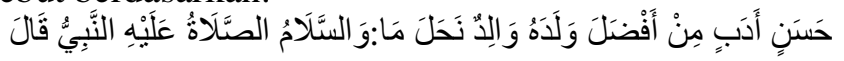

Artinya :

"Nabi Muhammad SAW bersabda : Tiada suatu pemberian yang lebih utama dari orang tua kepada anaknya selain pendidikan yang baik." (HR. Al Hakim: 7679)

Dari perkataan Ki Hajar Dewantara dan hadis di atas menunjukan bahwa orang tua memiliki peran yang sangat penting dalam kehidupan dan pendidikan anak, dan pendidikan murupakan pemberian utama dari orang tua untuk anak, berdasakan hal tersebut maka keselarasan pendidikan anak sangatlah penting.

Upaya agar selarasnya pendidikan anak di rumah dengan pendidikan anak yang didapat dari sekolah yaitu dengan adanya program pendidikan anak usia dini berbasis keluarga atau parenting, namun sayangnya program parenting masih belum tersebar secara luas di Indonesia, hal tersebut berdasarkan:

Prasurvei yang dilakukan terhadap 55 orang tua yang memiliki anak usia dini pada tiga kampung yang berbeda di Kecamatan Ibun hanya 2 diantaranya yang mengetahui dan 53 orang sisanya tidak mengetahui program pendidikan anak usia dini berbasis keluarga tau parenting.

Berdasarkan survei yang di lakukan KPAI pada tahun 2020 menunjukan program parenting yang diselenggarakan di sekolah hanya mencapai 33,3\%

Berdasarkan prasurvei kepada pengawas TK sekecamatan ibun bahwa TK IT X merupakan lembaga TK yang menjadikan program parenting sebagai program unggulan

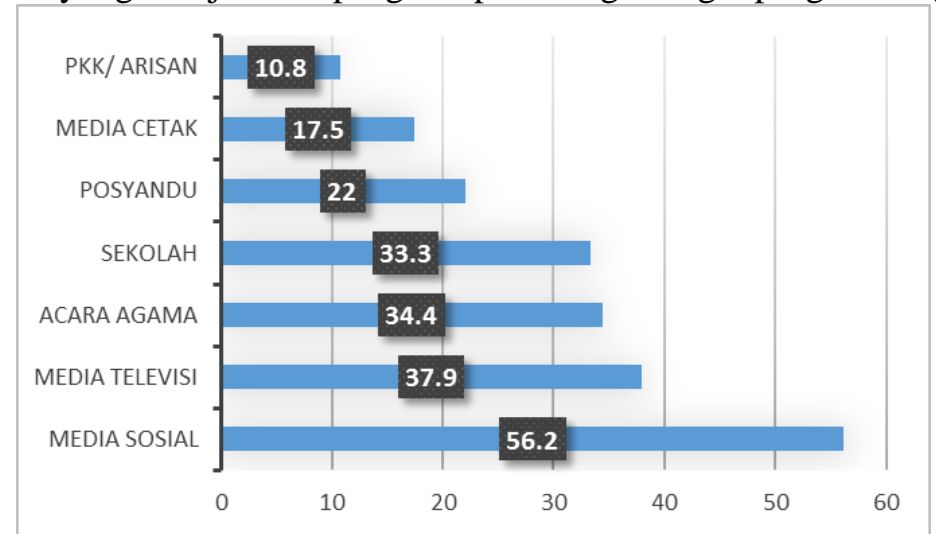

Dari data-data tersebut peneliti tertarik untuk meneliti terkait pengelolaan program parenting di TK IT X. Dengan tujuan penelitian (1) Untuk mengetahui apa saja dan bagaimana persiapan program parenting di TK IT X (2) Untuk mengidentifikasi terkait pelaksanaan program parenting di TK IT X (3) Untuk mengetahui terkait evaluasi program parenting di TK JRPGP is licensed under Creative Commons Attribution- 
IT X (4) untuk menemukan hasil program parenting yang dirasakan oleh orang tua siswa di TK IT X.

\section{B. Metodologi Penelitian}

Peneliti menggunakan pendekatan kualitatif dengan metode desktriptif, dengan 14 narasumber yang terdiri dari kepala sekolah, guru kelas, dan orang tua siswa. Dengan teknik pengumpulan data yaitu dengan wawancara kualitatif (Qualitatif Interview) (2), Meteri Audio dan Visual Kualitatif (Qualitatif audio and visual materials) (2), Observasi Kualitatif (Qualitatif Observation) (2). Adapun tekni Pengelolaan data 1) Reduksi data, (2) Penyajian data (3) Penarikan simpulan dan verifikasi (Hardani. Ustiawaty, 2017, p. 163). Keabsahan data melalui credibility (Triangulation atau triangulasi dan Referencial Adequacy Checks) transferability, dependability, dan confirmability (Suryana, 2007).

\section{Hasil Penelitian dan Pembahasan}

Berdasarkan buku pedoman program parenting yang diterbitkan oleh Direktorat Jenderal Pendidikan Anak Usia Dini, Nonformal dan Informal Kementrian Pendidikan Nasional 2012 (Kemdikbud, 2012) program parenting terdiri dari 3 tahap yaitu tahap persiapan, pelaksanaan, dan evaluasi:

\section{Persiapan program parenting di TK IT X Kecamatan Ibun}

Tahap persiapan terdiri dari 6 kegiatan (1): (1) Sosialisasi program parenting, yaitu pemberitahuan akan dilaksanakan program pendidikan anak usia dini berbasis keluarga atau parenting dapat dilakukan dengan berbagai macam cara seperti spanduk, pamflet, pertemuan, dan lainnya (2) Pembentukan pengurus program parenting, yaitu pembentukan panitia yang bertugas untuk mengkoordinasi pelaksanaan program parenting tersebut terdiri dari ketua, sekretaris, bendahara, seksi-seksi seperti konsumsi, acara, humas, dan lainnya. (3) Penyemaan persepsi yaitu menyelaraskan pemikiran dan memberikan penjelasan kepada orang tua terkait pendidikan anak usia dini berbasis keluarga atau parenting (4) Identifikasi kebutuhan belajar yaitu yaitu kegiatan mencari informasi terkait perilaku pengasuhan yang orang tua lakukan dirumah, hasil dari mengidentifikasi tersebut akan dijadikan sebagai bahan menyusun program pendidikan anak usia dini berbasis keluarga atau parenting (5) Penentuan tempat dan waktu, setelah mengidentifikasi kebutuhan orang tua atau peserta mengenai materi tahap selanjutnya adalah penentuan tempat dan waktu pelaksanaan program tersebut (6) Penyusunan program dan jadwal kegiatan, penyusunan dan jadwal program dibuat setelah menentukan waktu kemudian disusun dengan lebih rinci. Namun pelaksanaan tahap persiapan pada program parenting di TK IT X hanya terlaksana dua kegiatan yaitu sosialisasi program parenting dan penyamaan persepsi yang mana kedua kegiatan tersebut dilakukan pada rapat awal tahun bersama orang tua siswa.

\section{Pelaksanaan program parenting di TK IT X Kecamatan Ibun}

Dalam pelaksanaan program parenting terdapat beberapa bentuk kegiatan program parenting menurut (3) (4) dan hal tersebut juga dikemukakan dalam buku pendoman yang diterbitkan oleh Direktorat Jenderal Pendidikan Anak Usia Dini, Nonformal dan Informal Kementrian Pendidikan Nasional 2012 (1) yaitu (1) Kegiatan pertemuan orang tua (kelas orang tua), wadah untuk orang tua salinng berkomunikasi. Dapat dilakukan dengan berbagai macam jenis kegiatan: curah pendapat, sarahsehan, simulasi, belajar keterampilan tertentu. (2) Keterlibatan orang tua di kelas anak, adalah suatu kegiatan yang melibatkan orang tua dengan berbagai macam kegiatan: bermain dengan anak di dalam kelas, membantu guru dalam proses KBM, dan mengawasi pelaksanaan KBM anak di kelas. (3) Keterlibatan orang tua dalam acara bersama, adalah kegiatan yang melibatkan orang tua dalam kegiatan di luar kelas dapat dilakukan dengan berbagai jenis kegiatan seperti: wisata, bermain di alam, merayakan hari besar, merayakan hari besar, kunjungan, berkebun, bazar atau pameran. (4) Hari konsultasi orang tua, adalah hari yang di jadwalkan secara khusus atau tertentu untuk orang tua mengkonsultasikan terkait tumbuh kembang anak atau permasalahan yang di hadapi anak kepada pihak sekolah. (5) Kunjungan rumah atau home visiting, kunjungan rumah adalah kegiatan yang dilakukan oleh pihak sekolah atau ahli untuk memberikan bimbingan dan dukungan kepada orang tua dengan cara berkunjung secara langsung, bertujuan untuk memberikan penguatan terkait kapasitas orang tua dalam 
memberikan pengalaman berlajar (Oktavianingsih, 2019).

Sedangkan bentuk kegiatan dalam pelaksanaan di TK IT X terdiri dari: (1) Kegiatan pertemuan orang tua (kelas orang tua) dengan jenis kegiatan: curah pendapat dan sarahsehan, (2) Keterlibatan orang tua di kelas anak dengan jenis kegiatan: pekan muroja'ah, orang tua magang, dan pemberian makanan tambahan (PMT), (3) Keterlibatan orang tua dalam acara bersama dengan jenis kegiatan puncak tema dan family gathring dan yang terakhir (4) Hari konsultasi orang tua yang mana pelaksanaannya bersamaan dengan pembagian rapot. Dari 5 kegiatan yang dikemukakan oleh (3) (4) dan (1) hanya 1 kegiatan yang tidak dilaksanakan di TK IT X yaitu kunjungan rumah atau home visiting

\section{Evaluasi program parenting di TK IT X Kecamatan Ibun}

Evaluasi menurut buku pendoman yang diterbitkan oleh Direktorat Jenderal Pendidikan Anak Usia Dini, Nonformal dan Informal Kementrian Pendidikan Nasional 2012 (Kemdikbud, 2012) dapat dilakukan dengan 3 metode yaitu sebagai berikut: Focus Group Discussion (Diskusi Fokus), angket, wawancara dan observasi. Metode yang digunakan dalam tahap evaluasi di TK IT X adalah Focus Group Discussion (Diskusi Fokus), dan angket dengan menggunakan google form. Tahap evaluasi dilakukan untuk: (1) mengukur keberhasilan program parenting (2) memperbaiki dan meningkatkan program parenting, dan (3) sebagai landasan dalam penyempurna program. Sehingga evaluasi dilakukan bukan terkait hanya pelaksanaanya saja melainkan berserta dengan mengevaluasi pemahaman orang tua sebagai hasil dari program parenting yang dapat dilihat dari perubahan orang tua dalam memberikan pola asuh kepada anak. Namun pelaksanaan tahap evaluasi di TK IT X hanya terkait proses pelaksanaan program tersebut

\section{Evaluasi program parenting di TK IT X Kecamatan Ibun}

Orang tua terlibat aktif dalam program parenting yang diselenggarakan TK IT X sebagai peserta, orang tua merasakan manfaat yang didapatkan seperti menambah wawasan dan pengetahuan terkait parenting sehingga sedikit demi sedikit mengubah pola asuh orang tua dirumah menjadi lebih selaras dengan sekolah. Maknanya dengan adanya program parenting yang diadakan di TK IT X dan manfaat yang dirasakan orang tua yaitu bertambah pengetahuan atau wawasan orang tua, serta selarasnya pendidikan sekolah dengan pendidikan dirumah menjadikan tujuan pendidikan anak usia dini berbasis keluarga atau program parenting tercapai. Dan ketika tujuan program parenting sudah dapat tercapai, peran orang tua sebagai pendidik utama dan pertama juga dapat terpenuhi.

\section{Kesimpulan}

Berdasarkan pembahasan dalam penelitian ini, peneliti menyimpulkan beberapa hasil penelitian sebagai berikut:

1. Persiapan program parenting di TK IT X

Orang tua tidak dilibatkan dalam proses penyusunan program, penyusunan program parenting dilakukan oleh kepala sekolah dan didiskusikan dengan guru, kemudian orang tua diberi informasi melalui POMG dan surat resmi dari sekolah, kegiatan dalam tahap persiapan yang dilaksanakan terdiri dari 2 kegiatan yaitu: sosialisasi program parenting dan penyamaan persepsi yang mana kedua kegiatan tersebut dilakukan pada rapat awal tahun bersama orang tua siswa. 4 kegiatan yang tidak dilaksanakan oleh TK IT X adalah pembentukan pengurus program parenting, identifikasi kebutuhan belajar, penentuan tempat dan waktu, serta penyusunan program dan jadwal kegiatan.

2. Pelaksanaanprogram parenting di TK IT $X$

Dari ke-5 bentuk kegiatan pelaksanaan program parenting di TK IT X hanya satu yang tidak terlaksana yaitu kunjungan rumah, sedangkan 4 kegiatan lainnya terlaksana seperti kegiatan pertemuan orang tua dengan bentuk kegiatan yaitu: sarahsehan dan curah pendapat, keterlibatan orang tua di kelas anak dengan bentuk kegiatan yaitu: pekan muroja'ah, orang tua magang, dan pemberian makanan tambahan (PMT), keterlibatan orang tua dalam acara bersama dengan bentuk kegiatan puncak tema, dan Family gathring, dan yang terakhir adalah hari konsultasi orang tua. Materi yang diberikan antara lain menanamkan pendidikan karakter anak, membentengi anak di era digital, orang tua 
hebat dan shalih adalah fondasi, dan kajian ilmu agama.

3. Evaluasi program parenting di TK IT X

Evaluasi yang dilakukan di TK IT X menggunakan 2 metode yiatu penyebaran google form atau angket dan metode Focus Group Discussion (Diskusi Fokus). Evaluasi terkait dengan proses pelaksanaan parenting yang telah terlaksana.

4. Hasil program parenting yang dirasakan orang tua

Orang tua terlibat aktif dalam program parenting yang diselenggarakan TK IT X sebagai peserta, orang tua merasakan manfaat program parenting yaitu meningkatnya pemahaman orang tua terkait parenting dan bermanfaat terhadap pola pengasuhan orang tua di rumah menjadi lebih selaras dengan sekolah.

\section{Acknowledge}

Pertama peneliti bersyukur kepada Allah SWT yang telah memberikan kemudahan dan kekuatan dalam penyusunan penelitian ini, kemudian peneliti berterima kasih kepada kepada ibu dan bapa yang telah memberikan doa, dukungan, kasih sayang, arahan, cinta serta bimbingan, kepada Prof. Dr. H. Edi Setiadi, SH., MH. Selaku Rektor Universitas Islam Bandung, kepada Enoh, Drs., M.Ag Selaku Dekan Fakultas Tarbiyah dan Keguruan Universitas Islam Bandung, kepada Dr. Erhamwilda, Dra., M.Pd. Selaku Ketua Program Studi Pendidikan Guru Anak Usia Dini, kepada Dr. Masnipal, M.Pd Selaku dosen pembimbing 1 yang telah memberikan arahan, bimbingan dan mengerahkan waktu serta tenaganya dalam penyusunan penelitian ini, kepada Khambali, M.Pd.I Selaku dosen pembimbing 2 yang telah memberikan arahan, bimbingan dan mengerahkan waktu serta tenaganya dalam penyusunan penelitian ini, dan kepada seluruh keluarga besar dan sahabat-sahabat yang senantiasa mendoakan dan memberikan dukungan kepada peneliti.

Jazakumullah Khairan .

\section{Daftar Pustaka}

[1] Kemdikbud DPAUD. Penyelenggaraan pendidikan anak usia dini berbasis keluarga. 2012.

[2] Creswell JW. Research Design, Pendekatan Metode Kualitatif, kuantitatif, dan campuran. In: Achmad Fawaid dan Rianayati Kusmini Pancasari, editor. 4th ed. Pustaka Pelajar; 2016. p. 368.

[3] Hatimah I. Keterlibatan Keluarga Dalam Kegiatan Di Sekolah Dalam Perspektif Kemitraan. Pedagogia. 2016;14(2):290-7.

[4] Masnipal, Ansori I, Apriadi ADi. Pengelolaan Layanan Parenting Dalam PAUD Inkluasi. Bandung: The Southeast Asian Ministers of Education Organization Regional Centre for Ealy Childhood Care Education and Parenting; 2019.

[5] Qur'an. Kementerian Agama Ri; 